\title{
Identifying the rose varieties and natural forms using ISSR-markers
}

\author{
Olga Yu. Vasilyeva ${ }^{1 *}$, Olga V. Dorogina ${ }^{1}$, Sophia S. Yudanova ${ }^{1}$, Svetlana A. Plugatar ${ }^{2}$, and \\ Zinaida K. Klimenko ${ }^{2}$ \\ ${ }^{1}$ Central Siberian Botanical Garden, Siberian Branch of the Russian Academy of Sciences; 630090, \\ Novosibirsk, ul. Zolotodolinskaya, 101 \\ ${ }^{2}$ Nikitsky Botanical Garden, National Scientific Center of the Russian Academy of Sciences,298648 \\ Republic of Crimea, Yalta, pos.Nikita, Nikitsky spusk, 52
}

\begin{abstract}
Identifying among varieties and natural forms of roses were carried out using ISSR thechnics to determine kinship. It was studied 6 foreign varieties, 16 varieties bred in Nikitsky Botanical Garden, as well as 2 natural forms (Rosa canina and Rosa chinensis). Despite some samples breaking into three clades, many of them don't belong to any of these groups due to the lack of relative ties, that confirms the high genetic diversity in the studied material. The revealed molecular genetic differences in rose forms and varieties can be used to identify and certify cultivars promising for their complex resistance to the continental climate conditions.
\end{abstract}

\section{Introduction}

Roses, or rather various species and hybrids of representatives of the genus Rosa L., are the leading culture in the world decorative gardening. The Central Siberian Botanical Garden of SB RAS (CSBG SB RAS) has been long studying the complex resistance to the continental climate conditions among different rose varieties of Nikitsky Botanical Garden (NBG) selection. It carries out biomorphological studies of formation shoot systems (FSS), as well as a histochemical research of the seasonal dynamics of starch, sugars, proteins, lipids and shoot lignification processes.

As the representatives of the Rosa L. genus complex are a part of the CSBG's bioresource collection, to identify related forms the estimation of rose verities using molecular genetic technics has begun. Among molecular genetic tools, the most common and informative method is the analysis of electrophoretic spectra of inter-microsatellite DNA sequences (ISSR - Inter Simple Sequence Repeat). ISSR markers are used in genetics, phylogenetics, and breeding to study genetic diversity and differentiation of genotypes [1$3]$. Nowadays, the genetic identification is considered an urgent task of modern breeding.

Since representatives of the complex of the genus Rosa L. are part of the CSBG collection of biological resources, the evaluation of rose varieties using the molecular genetic method has begun. ISSR marker molecular genetic technique, widely spread to

\footnotetext{
* Corresponding author: vasil.flowers@,rambler.ru
} 
differentiate breeding material in various plant species [4-6], was used in the work. Molecular markers are characterized by a high level of polymorphism between varieties and can be effectively applied to assess general genetic characteristics.

The work objective is to determine the relationship between two natural forms and 22 varieties of foreign and NBG breeding from the CSBG SB RAS' collection.

\section{Material}

The verities involved in the study were: 6 foreign bred varieties, which are the parent forms (Dame de Cœur, Crimson Glory, Jacaranda, Queen Elizabeth, Excelsa, Popcorn); 16 varieties bred in NBG (Alisa, Ayu-Dag, Chatyr-Dag, Vesenniye Zvezdy, Gurzuf, Khersones, Zolotaya Osen, Komsomolsky Ogonyek, Koralovy Surpriz, Krymskoye Ozherelye, Krymskiy Samotsvet, Krymskiy Fakel, Lezginka, Letnye Zvezdy, Malchik-s-palchik, Professor Ivanov); as well as 2 natural species of Rosa canina and Rosa chinensis. The studied varieties belong to different garden groups.

\section{Method}

The study was carried out on dried leaves (herbarium material) of rose forms and varieties. DNA was isolated using the CTAB technique developed by J. Doyle [7] with some modifications. The method is based on cell lysis with cetyltrimethylammonium bromide buffer, deprotinization with chloroform, and DNA precipitation with isopropanol.

The polymerase chain reaction (PCR) was performed on a C-1000 thermocycler (BioRad, USA). The reaction mixture contained 1.5 units Taq DNA polymerase (Medigen, Russia, $5 \mathrm{u} / \mu \mathrm{l}$ ); $1 \times$ Taq-buffer without Mg2+ (Medigen, Russia); $2.3 \mathrm{mM} \mathrm{MgCl} ; 0.8 \mathrm{mM}$ dNTPs (Medigen, Russia); 0.8 mM ISSR primer (Medigen, Russia); DNA solution - $2 \mu$, water $\mathrm{mQH} 2 \mathrm{O}$ - up to $25 \mu \mathrm{l}$.

Amplification was carried out according to the following program: primary denaturation at $95^{\circ} \mathrm{C}-2 \mathrm{~min} ; 38$ cycles - denaturation $94^{\circ} \mathrm{C}-20 \mathrm{sec}$, primer annealing $-45 \mathrm{sec}(\mathrm{Ta}-$ annealing temperatures and nucleotide sequences are shown in Table 2), elongation - 1.5 min; final elongation -7 min. 8 primers were used for amplification. SYBR-Green I, an intercalating dye specific for double-stranded DNA, was applied as dye. Electrophoretic separation of amplification products was done in a 1-1.5\% agarose gel with $1 \times$ TBEbuffer.

The polymorphism quantitative assessment of applied markers and divergence level determination between the studied simples were based on state matrices of binary characters. The presence or absence of peptide components or PCR fragments of the same size were designated as states 1 or 0 .

To process the obtained data statistically, TREECON software package (version 1.3b) was used [8]. Genetic distances were calculated according to the formula:

$$
\mathrm{GD} x y=1-2 \mathrm{Nxy} /(\mathrm{N} x+\mathrm{N} y)
$$

where $\mathrm{N} x y$ - the number of common fragments for $x$ and $y$ samples, $\mathrm{N} x$ and $\mathrm{N} y$ - the number of fragments for $\mathrm{x}$ and y samples respectively [9]. Dendrograms were created using the Neighbor-Joining (NJ) algorithm with 100 bootstrap pseudo-replicas. The polymorphism percentage $(\mathrm{P}, \%)$ of each primer was calculated with the formula

$$
\mathrm{P}=100 \times \mathrm{N} p / \mathrm{N}
$$

where $\mathrm{Np}$ - the polymorphic fragment number, $\mathrm{N}$ - the total fragment number. 


\section{Results and discution}

Microsatellite DNA regions of the studied samples are analyzed using eight ISSR primers (Table 1). Each DNA band (amplified fragments) was treated as an independent character, being scored as present (1) or absent (0), resulting a binary data matrix which was used to compute primer banding characteristics such as: total number of bands (TNB), number of polymorphic bands (NPB), percentage of polymorphic bands (PPB). The studied primers have generated 175 amplified fragments (bands) from 250 to $2200 \mathrm{bp}$ in length, from which 164 were polymorphic. The number of fragments amplified by a primer range from 19 (UBC834) to 26 (HB-12) (Table 1). The polymorphism level detected by a single primer vary from 84.6 (amplified with HB-10) to $96 \%$ (with UBC-857), and averaged is $90.5 \%$. Fig. 1 shows the ISSR profile of the samples obtained by amplification with HB12 primer. The electrophoregram demonstrates a high polymorphism of electrophoretic spectra confirming the wide genetic diversity of the studied rose forms and varieties.

Table 1. Characteristics of ISSR primers tested and selected to study rose genetic polymorphism

\begin{tabular}{|l|l|c|c|c|c|}
\hline primers & Sequence, 5'-3' & $\mathbf{C}^{\circ}$ & TNB* $^{*}$ & NBP* $^{*}$ & PPB*, $\%^{* 1}$ \\
\hline HB 12 & $(\mathrm{CAC})_{3} \mathrm{GC}$ & $42^{\circ} \mathrm{C}$ & 26 & 23 & 88,46 \\
\hline 17899 A & $(\mathrm{CA})_{6} \mathrm{AG}$ & $49^{\circ} \mathrm{C}$ & 21 & 20 & 95,24 \\
\hline 17899 B & $(\mathrm{CA})_{6} \mathrm{GG}$ & $42^{\circ} \mathrm{C}$ & 23 & 22 & 95,65 \\
\hline UBC 807 & $(\mathrm{AG})_{8} \mathrm{~T}$ & $52^{\circ} \mathrm{C}$ & 22 & 21 & 95,45 \\
\hline UBC 834 & $(\mathrm{AG})_{8} \mathrm{YT}$ & $60^{\circ} \mathrm{C}$ & 19 & 18 & 94,74 \\
\hline UBC 855 & $(\mathrm{AC})_{8} \mathrm{YT}$ & $50^{\circ} \mathrm{C}$ & 25 & 23 & 92,0 \\
\hline M2 & $(\mathrm{AC})_{8} \mathrm{YG}$ & $50^{\circ} \mathrm{C}$ & 20 & 19 & 95,0 \\
\hline M9 & $(\mathrm{GACAC})_{4}$ & $50^{\circ} \mathrm{C}$ & 19 & 18 & 94,74 \\
\hline
\end{tabular}

* TNB - total number of bands, NPB - number of polymorphic bands, PPB - percentage of polymorphic bands, $\%$

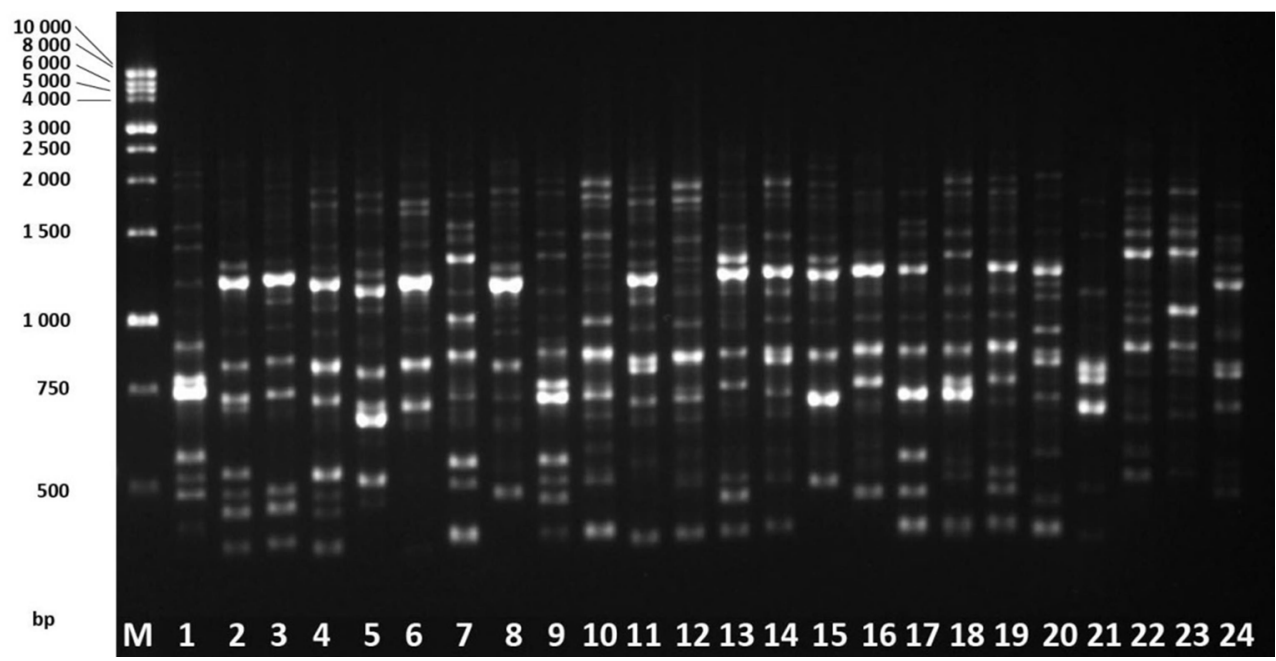

Fig. 1. Electrophoregram of PCR products obtained by DNA amplification of 24 rose samples and ISSR primer H12 (CAC CAC CAC GC). Track M - DNA marker, tracks with designation of samples: 1 Alisa, 2 - Krymskoye Ozherelye, 3 - Zolotaya Osen, 4 - Chatyr-Dag, 5 - Ayu-Dag, 6 - Krymskiy Fakel, 7 - Letnye Zvezdy, 8 - Krymskiy Samotsvet, 9 - Gurzuf, 10 - Professor Ivanov, 11 - Lezginka, 12 Koralovy Surpriz, 13 - Vesenniye Zvezdy, 14 - Queen Elizabeth, 15 - Khersones, 16 - Komsomolsky Ogonyek, 17 - Crimson Glory, 18 - Jacaranda, 19 - Dame de Cœur, 20 - Rosa canina, 21 - Rosa chinensis, 22 - Excelsa, 23 - Popcorn, 24 - Malchik-s-palchik. 
On the NJ-dendrogram (Fig. 2) the studied samples were divided into three clades, wich confirms the genetic diversity high degree. The first clade includes two natural forms of Rosa canina, Rosa chinensis and eight varieties bred in NBG (Krymskiy Fakel, Malchik-spalchik, Krymskiy Samotsvet, Ayu-Dag, Lezginka, Chatyr-Dag, Zolotaya Osen, Krymskoye Ozherelye).

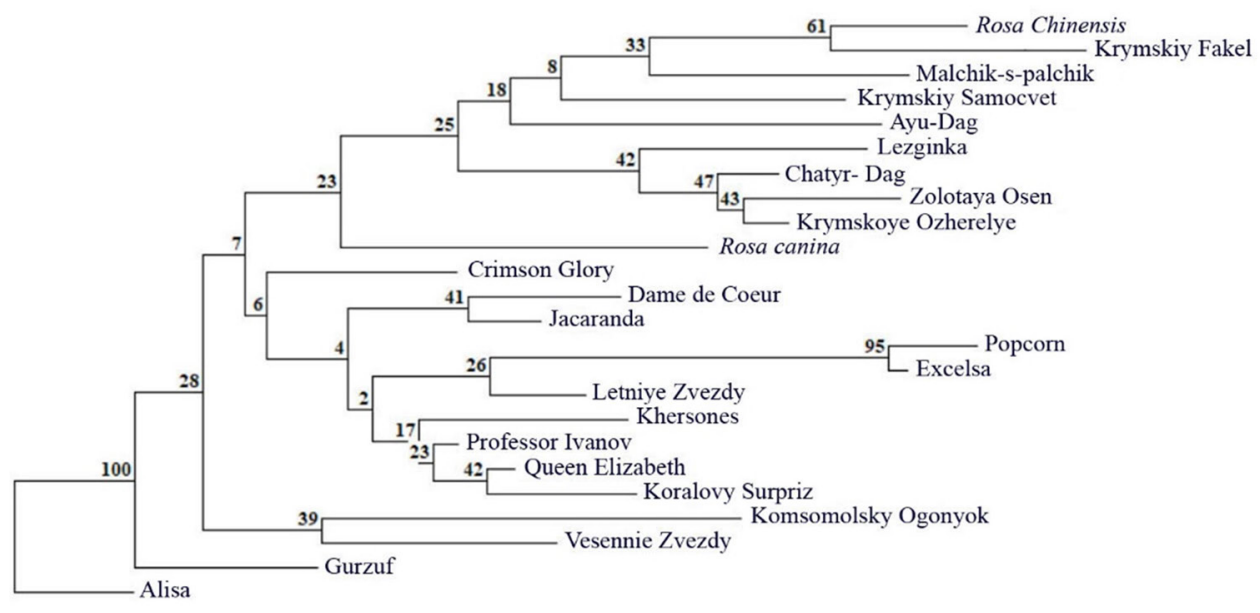

Fig. 2. Dendrogram built with the Neighbor-Joining (NJ) algorithm based on ISSR-PCR spectra data of 24 studied rose samples. Node numbers indicate the level of statistical branch bootstrap.

The second one embraces all foreign varieties (Queen Elizabeth, Crimson Glory, Jacaranda, Dame de Cœur, Excelsa, Popcorn), and several NBG varieties (Letniye Zvezdy, Khersones, Professor Ivanov); the third group consists of four varieties of NBG selection (Komsomolskiy Ogonek, Vesenniye Zvezdy, Gurzuf, Alisa). A high kinship degree is found in two American varieties Excelsa (breeder Michael H. Walsh, USA, 1908), and Popcorn (breeder Dennison H. Morey, USA, 1973). It should be noted that these varieties belong to different types of roses: Excelsa is included to the group of hybrids with Rosa wichuriana (currently Rosa lucieae), Popcorn is a miniature rose. Relative similarity is revealed between Rosa chinensis and the variety Krymskiy Fakel. It's not possible to establish relative ties for the remaining this group varieties, that indicates a wide genetic diversity of the selection material used to create them.

Despite some samples breaking into groups, many of them don't belong to any of these groups due to the lack of relative ties, that confirms the genetic diversity high degree of the studied material. In the first group they are Rosa canina natural form, Ayu-Dag and Krymskiy Samocvet varieties. The second and third groups mainly consist of varieties genetically diverse, although some of them form related pairs within the group.

Eight ISSR primers are tested on 22 varieties and 2 natural forms of roses in this work. The studies confirm that ISSR marker tool is quite suitable to investigate the origin of rose cultivars, and determine their genetic diversity degree. The revealed molecular genetic differences in garden rose forms and varieties can be used to identify and certify varieties promising for their complex resistance to the continental climate conditions.

This work was supported by the project of AAAA-A17-117012610053-9 "Identification of ways to adapt plants to contrasting habitat conditions at the population and organismic levels"

\section{Reference}


1. E. Zietkiewicz, A. Rafalski, D. Labuda, Genomics, 20, 176 (1994)

2. A. Patwardhan, S. Ray, A. Roy, J. Phylogen. Evolution. Biol., 2, 4 (2014)

3. T. Amom, P. Nongdam, Int. J. Cur. Res. Rev., 9, 1 (2017)

4. G. Harita, T. Sudhakar, D. Chandra, T. Ram, B. Divya, N. Sarla, Rice Sci., 23, 225 (2016)

5. G. Duta-Cornescu, C.-E. Pavlusenco, D. M. Pojoga, M. E. Negulici, N. Constantin, A. Simon-Gruita, AgroLife Sci. J., 6, 69 (2017).

6. A.-S. Tillault, D.P. Yevtushenko, Plant Direct. 3, e00140 (2019)

7. J. J. Doyle, J. L. Doyle, Phytochem. Bull., 19, 11 (1987)

8. Y. Van de Peer, R. De Wachter, Comput. Appl. Biosci. 10, 569 (1994)

9. M. Nei, W.-H. Li Proc. Natl Acad. Sci. USA, 76, 5269 (1979) 